\title{
Influence of Active Hydrogen Discharged from Palladium-Nickel Alloy Powder on Biological Cells
}

\author{
Aiko Motoishi, ${ }^{1, a}$, Akio Kagawa ${ }^{2, b}$, Makoto Matsuzaki ${ }^{1, c}$, \\ Kunihiko Tanaka ${ }^{3, d}$, Masataka Yamamoto ${ }^{2, e}$ and Yutaka Tagawa, ${ }^{3, f}$
}

${ }^{1}$ Graduate school, Nagasaki University, 1-14 Bunkyo-machi, Nagasaki, 852-8521, Japan.
${ }^{2}$ Division of Chemistry and Materials Science, Nagasaki University, 1-14 Bunkyo-machi,
Nagasaki, 852-8521, Japan.
${ }^{3}$ School of Medicine, Nagasaki university, 1-14 Bunkyo-machi, Nagasaki, 852-8521, Japan.

aemail:bb52112650@cc.nagasaki-u.ac.jp, bemail:akagawa@nagasaki-u.ac.jp, cemail: bb52111647@cc.nagasaki-u.ac.jp, demail:kunny-ta@nagasaki-u.ac.jp,

eemail:m-yamamoto@nagasaki-u.ac.jp, 'email:t-yutaka@youi-med.com

Keywords: Hydrogen, Palladium, Nickel, Hydrogen storage alloy, Hydrogen radical, Cancer cell

\begin{abstract}
A selective cancer cell death induced by discharged hydrogen from Pd-Ni base hydrogen storage alloy (HSA) powder is demonstrated. From the cell experiment and the measurement of surviving cell rate, it was found that cell death was seen only in cancer cells (HeLa : cervical cancer cell) after $24 \mathrm{~h}$ - and $48 \mathrm{~h}$-immersion of Pd-5at.\%Ni alloy powder, while no harmful influence was observed in normal cells (MDCK : renal epithelial cell). The range of cancer cell death was limited just near the HSA powder. It is suggested that the hydrogen radical emitted from the HSA powder induces the formation of hydrogen peroxide and brings a detrimental effect in the cancer cell, while hydrogen peroxide is decomposed by the enzyme, catalase, in normal cells, resulting in the selective death of cancer cells.
\end{abstract}

\section{Introduction}

It has been reported that hydrogen gas has an effect of reducing cytotoxic oxygen radicals and hence suppresses the occurrence of diseases caused by oxygen radicals, such as arteriosclerosis, cataract, blood-flow injury in brain, liver and heart and so on [1-5].

In an earlier work [6] on hydrogen storage alloys (HSAs), it has been clarified that Pd base solid solution alloy has an excellent workability and an easy activation characteristic. Furthermore, the desorption plateau pressure, i.e., hydrogen discharging rate, can be controlled by adjusting the alloy composition. On the desorption process, hydrogen absorbed in the metal lattice of the HSA moves to the metal surface to become an active hydrogen, i.e., atomic hydrogen. This atomic hydrogen (called "hydrogen radical") has a very high reactivity and is expected to have a protective action on the diseases caused by oxygen radicals.

In our preliminary work [7] on the application of HSA in the medical field, it has been found that discharged hydrogen from Pd-Ni base HSA causes cancer cell death. The existence of hydrogen radical $\left(\mathrm{H}^{*}\right)$ will be in a very short time, because of its instability due to a high reactivity, and gaseous hydrogen $\left(\mathrm{H}_{2}\right)$ can be easily formed through the reaction : $\mathrm{H}^{*}+\mathrm{H}^{*} \rightarrow \mathrm{H}_{2}$. Therefore, the effect of discharged hydrogen radical is to be limited in a narrow range near the HSA. The sample used is in a bulky form and hence the affected range of discharged hydrogen is limited depending on the sample shape and size. On the application of HSAs in disease treatment, a powder sample is desired for local disease treatments and the dosage of HSA is possible by using an injection of a biological saline solution in which the HSA powder is suspended.

In the present work, the hydrogen discharging behavior of Pd-Ni base HSA powder and the influence of the discharged hydrogen on biological cells have been investigated.

\section{Experimental}


Pd-5at.\%Ni alloy was prepared by arc-melting using pure materials (3N palladium and nickel) under argon gas atmosphere. The alloy was re-melted several times and annealed at $1073 \mathrm{~K}$ for $15 \mathrm{~h}$ in vacuum for homogenization. Then, the alloy was ground and the alloy powder (average diameter $<50$ $\mu \mathrm{m}$ ) was subjected to stress relief annealing at $923 \mathrm{~K}$ for $2 \mathrm{~h}$. A structural change in the as-ground sample and that after the stress relief annealing was examined by X-ray diffraction (XRD). Then, the alloy powder was hydrogenated using Sieverts type apparatus for the measurement of equilibrium hydrogen pressure, shown in Fig.1, and then heated at $723 \mathrm{~K}$ for $3 \mathrm{~h}$ in vacuum. These processes were repeated over three times for activation of the alloy surface.

In order to elucidate the effect of the stress relief annealing, hydrogen pressure changes on absorption and desorption with time were measured for the alloy powder before and after the annealing, using the apparatus shown in Fig.1. Pressure - composition (P-C) isotherms were measured for the powder sample and bulk sample $(2 \mathrm{~mm} \times 4 \mathrm{~mm} \times 80 \mu \mathrm{m})$ at $313 \mathrm{~K} \sim 373 \mathrm{~K}$.

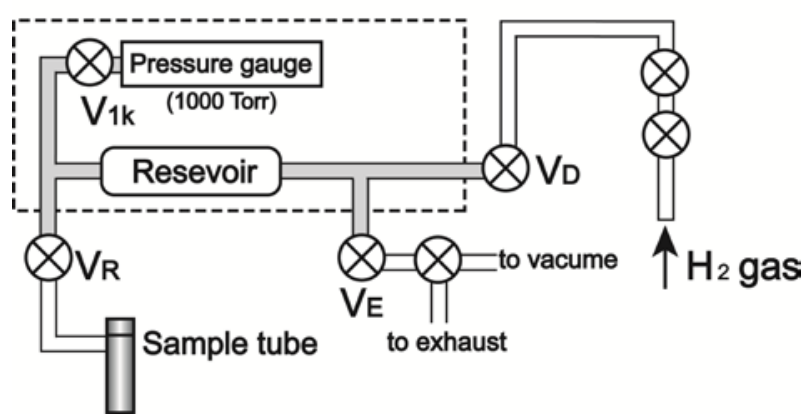

Fig.1 Schematic of Sieverts type apparatus.

Powder sample charged with hydrogen, denoted by $\mathrm{H}(+) \mathrm{HSA}$, and that free from hydrogen, denoted by $\mathrm{H}(-) \mathrm{HSA}$, were put in a laboratory dish (35 $\mathrm{mm}$ in diameter) containing cultured cancer cells (HeLa : cervical cancer cell) in medium solution. After incubating at $310 \mathrm{~K}$ for $24 \mathrm{~h}$ and $48 \mathrm{~h}$ under $5 \% \mathrm{CO}_{2}$ gas flow and $95 \%$ humidity, the biological cells were observed using an optical microscope. Then dead cells were stained by Trypan-blue reagent (dyeing for detection of dead cells) and the range of dead cells was measured using a stereomicroscope. The same experiments were performed for normal cells (MDCK: renal epithelial cell). The surviving rate of HeLa and MDCK cells cultured in the well of 24-well multi plate was measured using a cell counting kit (Cell Counting Kit-8), where the absorbance spectrum near $450 \mathrm{~nm}$ was detected using a visible-ultraviolet spectrophotometer.

For the detection of radicals arising from certain reactions with discharged hydrogen, the HSA powder charged with hydrogen, $\mathrm{H}(+) \mathrm{HSA}$, was dipped into distilled water. After 2 h, electron spin resonance (ESR) spectrum of the solution was analyzed.

\section{Results and discussion}

\section{Hydrogen Discharging Characteristics}

Fig.2 shows the shape and size of the as-ground HSA particles. The particle displays a scratched surface (Fig.2c), indicating an existence of strain. This suggests that the plastic strain induced on grinding possibly affects hydrogen absorption and desorption behavior. Therefore, the powder sample was subjected to a stress relief annealing at $723 \mathrm{~K}$ for $3 \mathrm{~h}$. XRD profiles of the powder samples before and after the stress relief annealing are given in Fig.3. After annealing, peaks become sharp, showing

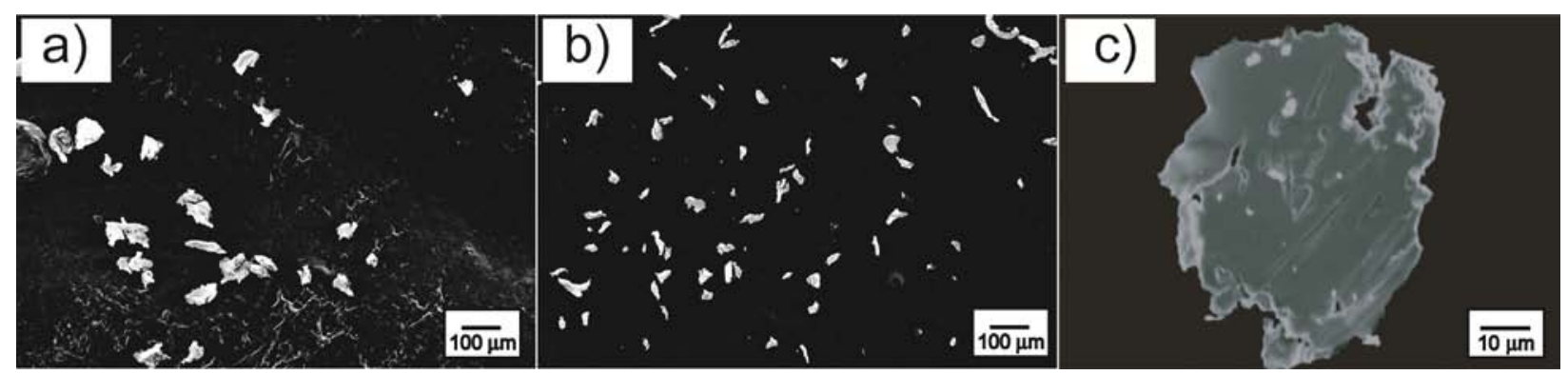

Fig.2 Shape and size of as-ground HSA particles. a) particle size of $20 \sim 53 \mu \mathrm{m}$, b) particle size of less than $20 \mu \mathrm{m}$ and c) particle shape in Fig.3a at high magnification. 
that the plastic strain is removed by the heat-treatment.

Fig. 4 shows the desorption isotherms at $313 \mathrm{~K} \sim 373 \mathrm{~K}$ for the annealed powder and bulk samples. Compared to the bulk sample, the maximum hydrogen content at $373 \mathrm{~K}$ is reduced and the plateau pressure is increased in the powder sample. It has been reported that HSA powder with a particle size
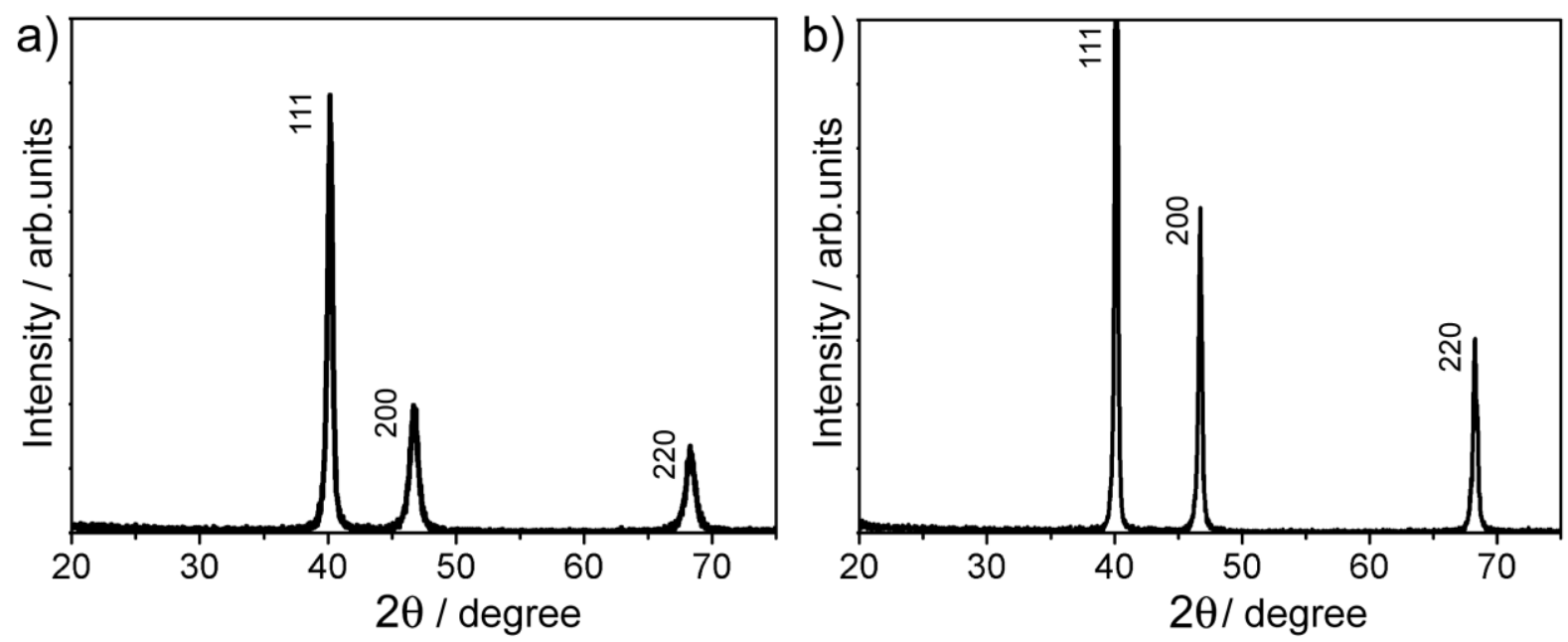

Fig.3 XRD profiles of alloy powder samples a) before and b) after stress relief annealing.

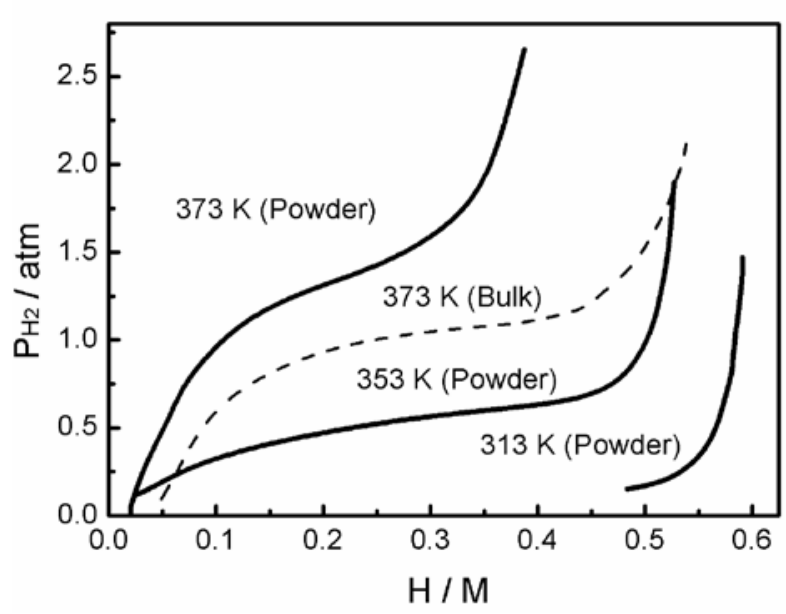

Fig.4 P-C isotherms on desorption at $313 \mathrm{~K}$ $\sim 373 \mathrm{~K}$ for HSA powder and bulk samples).

less than $50 \mu \mathrm{m}$ exhibits a significant reduction in the amount of absorped hydrogen [8]. The reduction in the maximum hydrogen content in the powder sample in Fig.4 is considered to arise from a similar effect of powder shape. In the powder sample, the hydrogen content is increased and the plateau pressure is lowered with decreasing temperature and the plateau pressure at $313 \mathrm{~K}$ is far lower than the atmospheric pressure. This indicates that although discharging of hydrogen is possible in air where the hydrogen partial pressure is zero, the discharging rate will be very slow, compared to the bulk sample. Fig. 5 shows a)

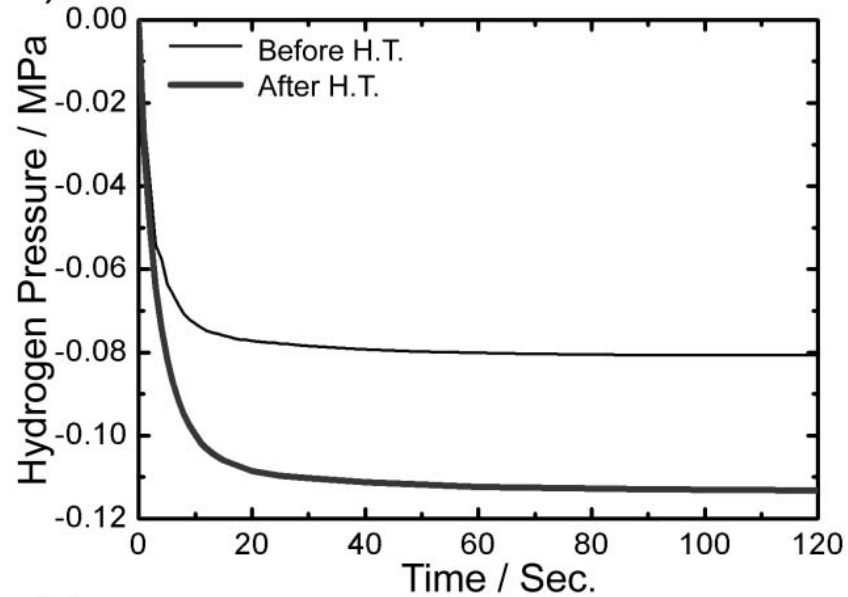

b)

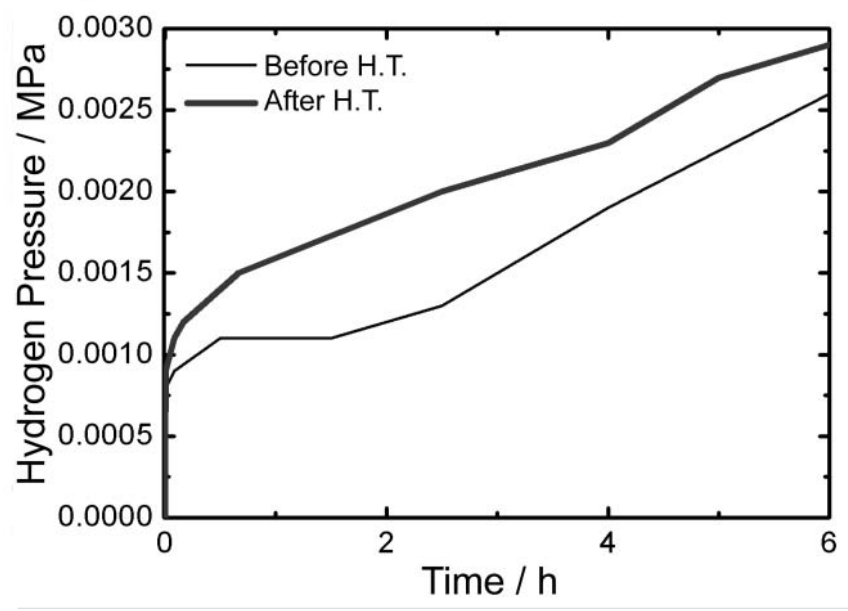

Fig.5 Kinetic curves of hydrogen a) absorption and b)desorption for HSA powder specimens before and after heat treatment (H.T.) for stress relief. 
kinetic curves of hydrogen absorption and desorption for the powder samples before and after the stress relief annealing. It is seen that the stress relief annealing effectively improves the hyrogen discharging rate as well as the amounts of absorbed and desorbed hydrogen.

\section{Biological Cell Experiment}

In the process of desorption, absorbed hydrogen in metal lattice moves to the metal surface to become an active hydrogen (hydrogen radical) which becomes gaseous hydrogen or hydrogen ion in an aq. solution unless other reactions occur.

However, the hydrogen radical has a very high reactivity and is expected to react with other species in the biological saline solution used in the cell experiment.

ESR measurement was performed to examine the existence of hydrogen radical and other reaction products. Fig.6 shows ESR spectrum of the biological saline solution after 2h-immersion of $\mathrm{H}(+) \mathrm{HSA}$ powder sample, where the peaks for hydrogen radical $\left(\mathrm{H}^{*}\right)$ and hydroxyl radical (HO^) are detected. The latter is considered to be a reaction product : $2 \mathrm{H}^{\circ}$ $+\mathrm{O}_{2} \rightarrow \mathrm{H}_{2} \mathrm{O}_{2}$ and $\mathrm{H}^{\cdot}+\mathrm{H}_{2} \mathrm{O}_{2} \rightarrow \mathrm{H}^{+}+\mathrm{HO}$ $+\mathrm{HO}^{\circ}$.

Fig.7 shows the appearance of cultured HeLa cells after 24h-immersion of $\mathrm{H}(+)$ HSA powder $(\mathrm{a}, \mathrm{b})$ and bulk $(\mathrm{e}, \mathrm{f})$ samples together with that of cultured MDCK cells (c, d). The dead cells are stained with Trypan-blue reagent. The dark blue area in Fig.7b, 7e and 7f shows the region of cell death. In the powder sample (Fig.7a,b), the range of cell death is limited just near the HSA powder. This is due to the size effect. A similar size effect is seen at the needle end in Fig.7f. In the cylindrical sample, cell death is seen in the region of $2 \sim 3 \mathrm{~mm}$ from the sample (Fig.7e). In the normal cells (MDCK) , no stained region is observed around the HSA powder (Fig.7d), indicating no influence of discharged hydrogen on MDCK cells.

The absorbance intensity at $450 \mathrm{~nm}$ for normal and cancer cells after $24 \mathrm{~h}$ - and 48h- immersion of $\mathrm{H}(+) \mathrm{HSA}$ powder sample is shown in Fig. 8 ((a) normal cells (b) cancer cells). The decrease in the absorbance intensity means an increase in dead cells in Fig.8a. Cell death is seen only in the cancer cells after 48h-immersion of $\mathrm{H}(+)$ HSA powder

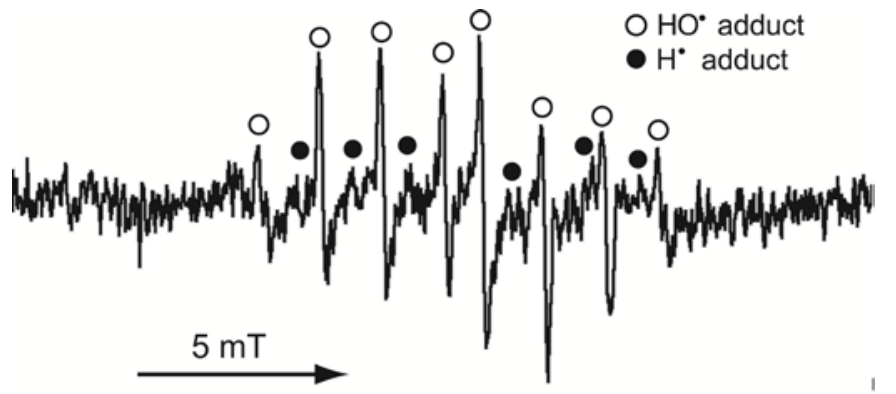

Fig.6 ESR spectrum of the biological saline solution after $2 \mathrm{~h}$-immersion of Pd-5at.\%Ni HSA powder sample.

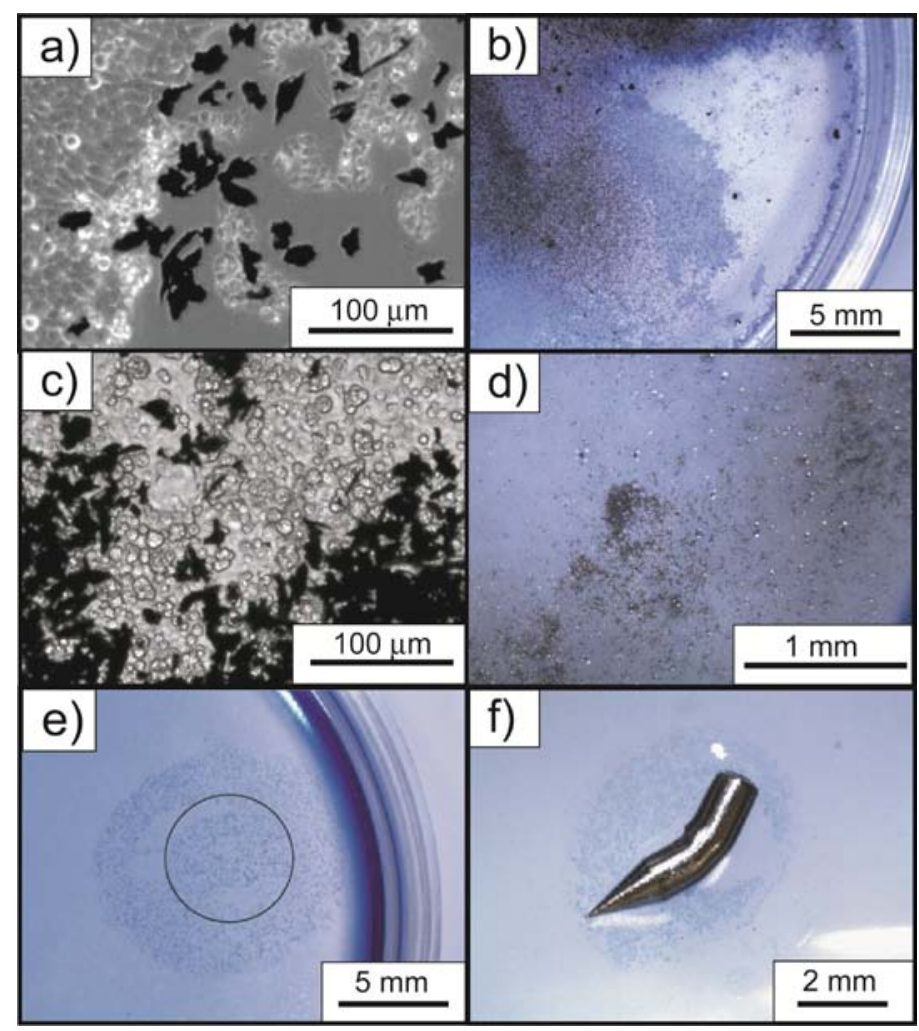

Fig.7 Appearance of cultured HeLa cells after 24h-immersion of Pd-5at\%Ni HSA powder.

a) and b) HeLa cells near HSA powder,

c) and d) MDCKcells near HSA powder,

e) stained dead cells near the HSA having a cylindrical shape. and f) stained dead cells near the HSA having a needle shape.

(a, c) : under optical microscope (b,d,e,f) : under stereomicroscope 
sample. No significant difference is detected in the absorbance intensity after 24h-immersion of for $\mathrm{H}(+) \mathrm{HSA}$ and $\mathrm{H}(-)$ HSA powder samples, indicating that the region of cell death is localized near the powder within the blue-colored region. However, a significant difference $(P<0.05)$ is obtained between them after 48h-immersion. On the other hand, in MDCK normal cells, the absorbance intensity increases in the case of immersion of $\mathrm{H}(+) \mathrm{HSA}$ powder sample, i.e., the rate of surviving cell increases, compared with the case of $\mathrm{H}(-) \mathrm{HSA}$ powder sample immersion, suggesting a positive influence of hydrogen on the normal cells. The result in Fig.8 clearly reveals that the discharged hydrogen from the HSA exhibits a selective influence, i.e., cell death is induced only in cancer cells and no harmful influence in normal cells.

It is well known that cytotoxic superoxide anion is generated in mitochondria [9]. Then, superoxide dismutase converts superoxide anion into harmful hydrogen peroxide [10] and the enzyme, catalase, detoxifies hydrogen peroxide into harmless water in normal cells. However, cancer cells are poor in catalase. Then, very harmful reactive oxygen species (ROS), such as hydrogen peroxide and hydroxyl radical, are possibly produced in cancer cells. Therefore, it is inferred that the hydrogen radical emitted from the HSA induces the formation of harmful ROS and bring a detrimental effect in cancer cells, while hydrogen peroxide is decomposed by the enzyme (catalase) in normal cells, resulting in the selective death of cancer cells.
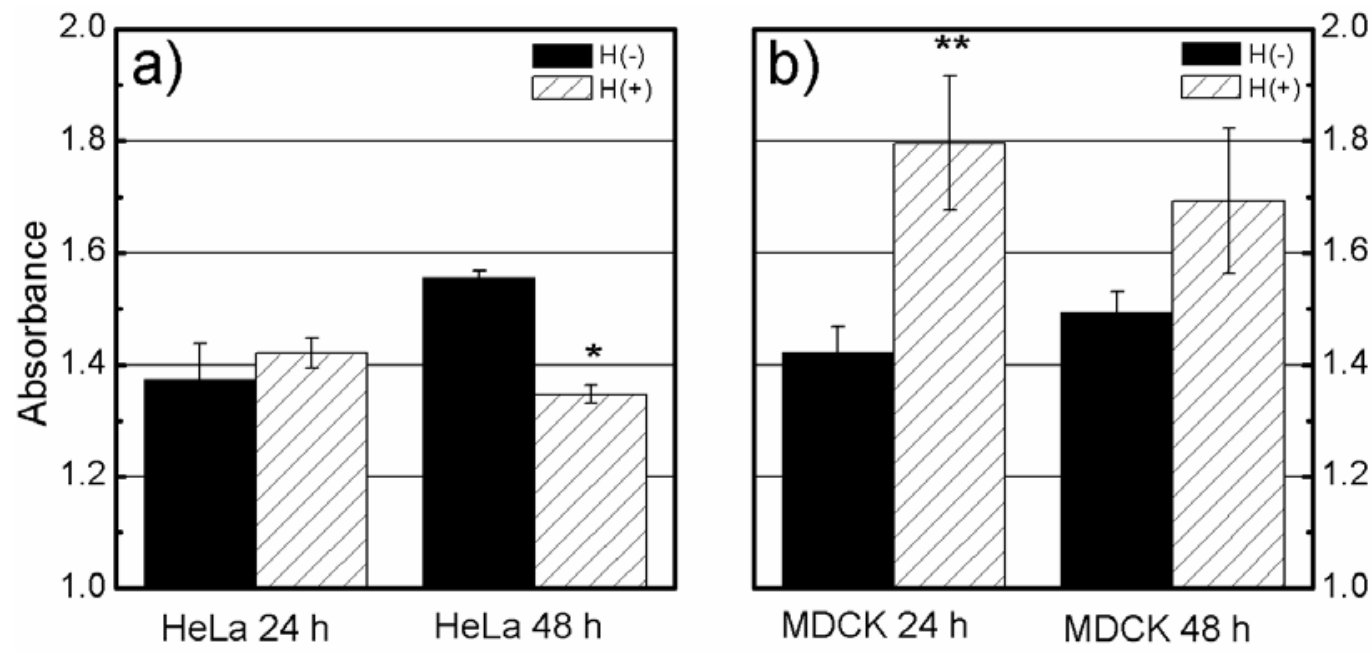

Fig.8 The absorbance intensity of a) normal cells and b) cancer cells after 24h- and 48himmersion of Pd-5at.\% Ni HSA powder samples. Histograms represent mean \pm s.d. ${ }^{*} P<0.05$ and ${ }^{* *} P<0.01$, by Student's t-test $(\mathrm{n}=4)$.

\section{Summary}

The hydrogen discharging behavior of the Pd-Ni alloy powder and the influence of hydrogen discharged from the alloy on biological cells has been investigated.

The stress relief annealing of the alloy powder effectively improves the hydrogen discharging rate as well as the amounts of absorbed and desorbed hydrogen.

The cell experiment reveals that HeLa cancer cells are extinct after 48h-immersion of Pd-5at.\%Ni HSA powder sample and the range of cancer cell death is limited just near the HSA powder.

From the measurement of surviving cell rate of MDCK normal cells and HeLa cancer cells, it has been found that the discharged hydrogen from the HSA exhibits a selective influence, i.e., cell death is induced only in cancer cells and no harmful influence in normal cells. This selective death of cancer cells is explained from the fact that cancer cells are poor in the enzyme (catalase) that decomposes hydrogen peroxide into water. 


\section{Acknowledgement}

This research was partially supported by the Ministry of Education, Culture, Sports, Science and

Technology, Grant-in-Aid for Scientific Research (C), 24500512, 2012.

\section{References}

[1] I. Ohsawa, M. Ishikawa, K. Takahashi, M. Watanabe, K. Nishimaki, K. Yamagata, K. Katsura, Y. Katayama, S. Asoh and S. Ohta : Nat. Med. Vol.13 (2007) , p.688

[2] K. Fukuda, S. Asoh, M. Ishikawa, Y. Yamamoto, I. Ohsawa and S. Ohta : Biochem. Biophys. Res. Commun. Vol.361 (2007), p.670

[3] J. Cai, Z. Kang,W.W. Liu, X. Luo, S. Qiang, J.H. Zhang, S. Ohta, X. Sun, W. Xu, H. Tao and R. Li : Neurosci. Lett. Vol.441 (2008) , p.167

[4] K. Hayashida, M. Sano, I. Ohsawa, K. Shimura, K. Tamaki, K. Kimura, J. Endo, T. Katayama, A. Kawamura,S. Kohsaka, S. Makino, S. Ohta, S. Ogawa and K. Fukuda : Biochem. Biophys. Res. Commun. Vol.373 (2008), p.30

[5] B.K. Buchholz, D.J. Kaczorowski, R. Sugimoto, R. Yang, Y. Wang, T.R. Billiar, K.R. MacCurry, A.J. Bauer and A. Nakao : Am. J. Transplant. Vol.8 (2008), p.2015

[6] M. Mizumoto, T. Ohgai and A. Kagawa : J. Alloys Compd. Vol. 482 (2009), p.416

[7] A. Kagawa, K, Katsura, M. Mizumoto, Y. Tagawa and Y. Mashiko : Mater. Sci. Forum, Vol.706-709 (2012), p.520

[8] J.H. Kim, H. Lee, K.T. Hwang and J.S. Han : J. Hydrogen energy Vol.34 (2009), p.9420

[9] C. Chinopoulos and V. Adam-Vizi : FEBS J. Vol.273 (2006), p.433

[10] J.F. Turrens : J. Physiol. (London) Vol.552 (2003), p.335 